\title{
The Impact of the Differential White Blood Cells in the Diagnosis of the Acute Right Iliac Fossa Pathology
}

\author{
Hazim Abdul Rahman Alhiti 1, (D), Manaf A. Guma ${ }^{2, *(\mathbb{D})}$, Tahir Rissan Dikheel ${ }^{3(\mathbb{D})}$, \\ Lorenza Francescut 4 (i) \\ 1 Nursing School Al Anbar Directorate of Health, Iraq \\ 2 Department of Applied Chemistry, College of Applied Sciences - Hit, University Of Anbar, Iraq \\ 3 Economic and Management Department, Al Qadisiyah University, Iraq \\ 4 Champion Mental Health First Aider, Department of Molecular and cell Biology, College of Sciences, Henry Welcome \\ Building, University of Leicester, UK \\ * Correspondence: manafguma@uoanabr.edu.iq;
}

Received: 18.02.2020; Revised: 25.04.2020; Accepted: 27.04.2020; Published: 2.05.2020

\begin{abstract}
Acute Right Iliac Fossa Pain is a common symptom which has shown diagnostic difficulties for the surgical emergency clinic. A White Blood Cells test is required for Acute Right Iliac Fossa Pain diagnosis. In this study, we aimed to clarify the importance of Differential White Blood Cells test for Acute Right Iliac Fossa Pain diagnosis. The present observational study was conducted in in Heet General Hospital over a period of five months included 62 patients from both genders of different ages (5-45 years) who were suffering from Acute Right Iliac Fossa Pain. All patients were subjected to Differential White Blood Cells test which was carried out in the hospital laboratory using (Hematology Pentra 60 Series HORIBA ABX SAS). A statistical analysis were then run using ANOVA and LSD tests. The analysis have shown the means of each type as follow; NEU (8.3516), LYM (31.2984), MON, (6.1952), GRA (62.6790) 10^3/mm3. Also, a comparison among all the WBCs types and also between and within groups was performed using one and two ways Analysis of Variance ANOVA tests which have shown that there are significant differences of all differentials WBCs types. $p<0.05$ was considered statistically significant. Based on our findings, it can be clearly stated that Differential White Blood Cells tests (not only WBC) are very important for the clear diagnosis of Acute Right Iliac Fossa Pathology.
\end{abstract}

Keywords: Heet (Hit) General Hospital; Differential White Blood Cells; Right Iliac Fossa Pain.

(C) 2020 by the authors. This article is an open access article distributed under the terms and conditions of the Creative Commons Attribution (CC BY) license (https://creativecommons.org/licenses/by/4.0/).

\section{Introduction}

Acute Right Iliac Fossa Pain is a common symptom that is a challenge for the surgical emergency clinic $[1,2]$. It is also the most frequent conditions treated in the Emergency hulls $[3,4]$. The diagnostic uncertainty for the RIF pain presents a variation in the investigation and an inaccurate treatment [5]. The symptom also gives rise to a wide range of suspicion diagnostic to the surgeon [6]. Moreover, the assessment of the abdominal pain in the children and pregnancy results in an inaccurate diagnosis due to other factors that can be involved in the evaluation.

The most recurrent symptom that can be suspected in acute RIF cases as appendicitis. Therefore, Laboratory examinations must be performed for every case of Acute RIF Pain to highlight the specific characteristic parameters. The examinations include a general urine test, white blood cells test, and other additional tests depending on the case [7]. The easiest, fastest 
and precise test can be performed is the white blood cell test (WBCs). WBCs are the defense cells in the blood which mainly consist of the following types: neutrophils, lymphocytes, eosinophils, basophils \& monocytes [8]. White blood cell count (in its simplistic form) is a common test that is primarily accomplished for such symptoms. The test is usually called for diagnosing, monitoring of infection and assessing in the discovery of many immunological disorders [9]. Hematology Pentra 60 Series HORIBA ABX SAS is a hematology analyzer for Diagnosing $[10,11,12]$.

Currently, the different types of differential WBCs are examined using a dependable hematological machine which calculates the whole blood count that is used for diagnosing anemia, infections, types of cancer and autoimmune diseases [8]. The various pathologies which are presented in the Right Iliac Fossa as an acute pain need to be elucidated using the variation on differential White blood cell percentage or the count. Diagnosis of the pathologies presents in the Right Iliac Fossa as an acute pain does not depend on the differential WBCs per se, it is rather a complicated procedure that includes a perfect history taking, a smart clinical diagnosis, and available radiological and laboratory exploration and a wise judgment [13].

Previous studies in the diagnosis of RIF have focused on acute appendicitis only. Our current study aim is to clarify the importance of the differential White Blood Cells test in the diagnosing of Acute Right Iliac Fossa Pain [13].

\section{Materials and Methods}

The study has been performed for over five months in Heet General Hospital involved 62 consecutive patients from both genders of different ages (5-45 years) who complained from Acute Right Iliac Fossa Pain. Differential White Blood Cells test was requested to be assessed in our hospital laboratory by Hematology Pentra 60 Series HORIBA ABX SAS. The data of all were collected and statistical analysis was performed using SPSS statistical software. statistical analysis by ANOVA and comparison of variables, then Least Significant Difference test (LSD) were used for the detection of the significant WBC type among them. Significant $\mathrm{P}$-value is $<0.05$. The expected percentages of the normal differential WBCs were considered as in Table 1 which are adopted by the machine supplier.

Table 1. Shows normal reference (expected values) of the WBC according to CBC machine: Hematology Pentra 60 Series HORIBA ABX SAS.

\begin{tabular}{|l|l|l|l|}
\hline WBC 103/mm3 & LYM \% & \multicolumn{1}{c}{ MON \% } & GRA \% \\
\hline $4.1-10.5$ & $16.0-43.3$ & $2.8-10.2$ & $48.5-80.3$
\end{tabular}

\section{Results and Discussion}

Over the five-month period, a total of 62 patients were attending to the general surgical team with acute RIF pain. More males 34 (54.8\%) presented with RIF pain than females 28 (45.1\%). The differential WBC test was involved with other tests that must be obtained to facilitate the diagnosis. Most of the differential WBC tests' results were showing abnormality. Thus, their data were collected and analysed. The statistical analysis for the taken patients has shown significant differences of all differentials WBCs among all the groups which the means of NEU (8.3516), LYM (31.2984), MON, (6.1952), GRA (62.6790) $10^{3} / \mathrm{mm}^{3}$. ANOVA oneand two-ways methods were used in the comparison and also (LSD test) was evaluated. The analysis showed that there are significant differences between these groups (seen in tables 1, 2 and 3). 


\subsection{Discussion.}

Right Iliac fossa (RIF) pain is one of the most common symptoms that are presented to acute general surgical services [14, 15]. Frequently, causes of the pain involved gastrointestinal, gynecological, appendicitis, urological, vascular and also musculoskeletal pathologies [16-18]. It is important to monitor the response of treatment for medical case establishment, like Lymphoma or leukemia patients with right RIF. Our study focused primarily on the most important examination that could lead easily to the acute RIF diagnosis. Differential WBC test is the case.

In comparison to previous studies published in the literature about pain in the RIF [7], our study showed the relativity of the WBC examination to the acute RIF pain. The statistical analysis of the collected data showed notable variability in the different types of WBCs. The majority ranged out of 62 patients was between 34 males $(54.8 \%)$ and 28 females $(45.1 \%)$ within six months. Other contributions of our study are to look for the influenced type of differential WBC by the acute RIF. Although the sample size is relatively small to the standard numbers of the statistic studies due to the unavailability of the CBC machine in the night shift in our local hospital, however, the analysis of data is highly conclusive and informative [19]. As seen in Table 2, the mean of each WBC type differs among the all according to the normal count of each cell type. This is probably due to the fact that all the WBC cells work together to defend the body against microbes which threaten the body's immune system [20]. The table also shows that there is at least one type of WBC type significantly differs from others, which indicates the null hypothesis is wrong (no difference between WBC types). Although it shows a normal distribution of WBC types, it gives the surgeon the clue to the absence of cancers or autoimmune disease $[19,21,22]$.

The analysis between groups and also within groups of WBC types are shown in Table 3. It shows the differences between the WBC types. There is a significant difference between WBC types, which gives the surgeon a clue to the normal patient body response to infection [23-25].

Table 4 shows the comparison between WBC types seeking for the specific WBC type similarity and differences, therefore, Least Significant Difference test (LSD) was performed. The results show that there is a similarity between NEU (neutrophils) \& MON (monocytes) in our results which coincides with previous studies [26-28].

In the meanwhile, it is emphasized to the surgeon to exclude the causes of Monocities in adults \& children $[21,22,23]$.

There is a significant difference between each specific WBC type from the others, which explains the acute pathological process $\&$ excludes the medical or chronic process, this is similar to previous papers [29-31].

Figure 1 shows the distribution of WBC types according to our results, the expected distribution of WBC cell types and also the unusual changes in the curve could guide the surgeon us to non-surgical diagnoses. Therefore, the test is the most important differential diagnosis of acute right iliac fossa pain [32-34]. On the other hand, another statistical analysis has shown (results are not shown) that there is no significance in terms of gender variation among all the differential WBC types. Since the acute right iliac fossa pain is the most common surgical presentation and sometimes the most difficult one, where we could present the property of the WBC examination as a first marker for the acute RIF pain. 


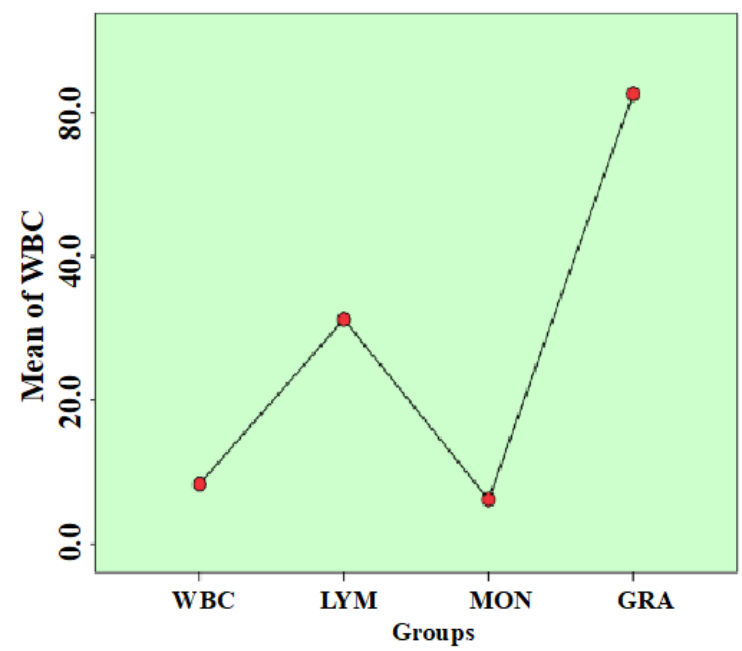

Figure 1. shows the distribution of differential WBC groups verse the mean of WBC.

Table 2. Shows the mean, $95 \%$ confidence interval standard deviation and error of each WBC type according to the normal count.

\begin{tabular}{|c|c|c|c|c|c|c|c|c|}
\hline \multicolumn{9}{|c|}{ Descriptive comparison of the deferential WBC } \\
\hline & \multirow[b]{2}{*}{$\mathbf{N}$} & \multirow[b]{2}{*}{ Mean } & \multicolumn{2}{|c|}{ Std. } & \multicolumn{2}{|c|}{ 95\% Confidence Interval for Mean } & \multirow[b]{2}{*}{ Minimum } & \multirow[b]{2}{*}{ Maximum } \\
\hline & & & Std. Deviation & Error & Lower Bound & Upper Bound & & \\
\hline $\mathrm{Neu}$ & 62 & 8.3516 & 3.32224 & 0.42193 & 7.5079 & 9.1953 & 3.80 & 20.00 \\
\hline LYM & 62 & 31.298 & 12.90603 & 1.63907 & 28.0209 & 34.5759 & 6.00 & 55.20 \\
\hline MON & 62 & 6.1952 & 3.49883 & 0.44435 & 5.3066 & 7.0837 & 1.20 & 20.00 \\
\hline GRA & 62 & 62.679 & 13.50347 & 1.71494 & 59.2498 & 66.1083 & 38.60 & 90.20 \\
\hline Total & 248 & 27.13 & $\begin{array}{ll}0 & 24.73894\end{array}$ & 1.57092 & 24.0369 & 30.2252 & 1.20 & 90.20 \\
\hline
\end{tabular}

Table 3. Shows the differences between the WBC types between groups and also within groups of WBC types.

\begin{tabular}{c|c|c|c|c|c}
\multicolumn{7}{c}{ ANOVA one- and two-ways analysis for WBC } \\
Sum of Squares & df & Mean Square & F & Sig. \\
\hline Between Groups & 128464.275 & 3 & 42821.425 & 460.212 & 0.000 \\
\hline Within Groups & 22703.496 & 244 & 93.047 & & \\
\hline Total & 151167.771 & 247 & & &
\end{tabular}

Table 4. Shows the comparison between WBC types and seeks for the specific WBC type similarity and difference, so we use Least Significant Difference test (LSD).

\begin{tabular}{|c|c|c|c|c|c|c|c|}
\hline \multicolumn{8}{|c|}{ Dependent Variable: WBC, Multiple Comparisons } \\
\hline & \multirow[b]{2}{*}{ (I) groups } & \multirow[b]{2}{*}{ (J) groups } & \multirow[b]{2}{*}{ Mean Difference (I-J) } & \multirow[b]{2}{*}{ Std. Error } & \multirow[b]{2}{*}{ Sig. } & \multicolumn{2}{|c|}{ 95\% Confidence Interval } \\
\hline & & & & & & Lower Bound & Upper Bound \\
\hline \multirow[t]{6}{*}{ LSD } & Neu & MON & 2.15645 & 1.73249 & 0.214 & -1.2561 & 5.5690 \\
\hline & \multirow[t]{2}{*}{ LYM } & $\mathrm{Neu}$ & $22.94677 *$ & 1.73249 & 0.00 & 19.5342 & 26.3593 \\
\hline & & MON & $25.10323 *$ & 1.73249 & 0.00 & 21.6907 & 28.5158 \\
\hline & \multirow[t]{3}{*}{ GRA } & Neu & $54.32742 *$ & 1.73249 & 0.00 & 50.9149 & 57.7400 \\
\hline & & LYM & $31.38065^{*}$ & 1.73249 & 0.00 & 27.9681 & 34.7932 \\
\hline & & $\mathrm{MON}$ & $56.48387 *$ & 1.73249 & 0.00 & 53.0713 & 59.8964 \\
\hline
\end{tabular}

\section{Conclusions}

This study highlights the importance of a differential in the white count in the diagnosis of RIF pain. We can see that the lymphocyte count and granulocyte counts are significantly raised, although within the normal range, however, the other differential markers are not significantly raised. We can see that although the differential counts are raised, it is nonspecific, which could indicate any acute inflammatory process. Therefore, the strengths of the analysis indicate that checking the differential white cell count is useful to guide further management, however, the weakness lies in the fact that it is a non-specific marker. The study could have been improved by analysing the results with the diagnosis of the condition, we may have therefore been able to check the true significance at a clinical level. The study, therefore, 
indicates that a differential white cell count is more useful in guiding clinicians on what further management may be required such as surgical intervention. About the limitation, there is a relatively small sample size.

\section{Funding}

This research received no external funding

\section{Acknowledgments}

We greatly thank our friends: Anees Adel Hijazeen (responsible of statistics), Dr. Mohammed Jasim Mohammed (College Of Administration \& Economics, University of Baghdad) and Dr Syed Salman Ashraf (m) Clarendon Park Medical Centre, Leicester, UK. Many thanks to all patients \& laboratories staff who assist our work.

\section{Conflicts of Interest}

The authors declare no conflict of interest.

\section{References}

1. Raghavan, S.N.; Raveendran, S.; Vamanaprabhu, R.R. Evaluation of modified Alvarado score in diagnosis of acute appendicitis-a prospective study comparing the score with histopathology. J Evolution Med Dent Sci 2017, 6, 2391-2395.

2. Ahmed, O.; Rogers, A.; Balfe, P.; Waldron, B.; Pretorius, F.; McMonagle, M. Clinical utility of abdominal and pelvic ultrasound in the evaluation of right iliac fossa pain in females. Irish Journal of Medical Science 2017, 186, 775-779, https://doi.org/10.1007/s11845-017-1557-4.

3. McCartan, D.; Fleming, F.; Grace, P. The management of right iliac fossa pain-Is timing everything? The surgeon 2010, 8, 211-217, https://doi.org/10.1016/j.surge.2009.11.008.

4. Atema, J.J.; van Rossem, C.C.; Leeuwenburgh, M.M.; Stoker, J.; Boermeester, M.A. Scoring system to distinguish uncomplicated from complicated acute appendicitis. Br J Surg 2015, 102, 979-990, https://doi.org/10.1002/bjs.9835.

5. Atema, J.J.; Gans, S.L.; Beenen, L.F.; Toorenvliet, B.R. Laurell, H.; Stoker, J.; Boermeester, M.A. Accuracy of white blood cell count and C-reactive protein levels related to duration of symptoms in patients suspected of acute appendicitis. Acad Emerg Med 2015, 22, 1015-1024, https://doi.org/10.1111/acem.12746.

6. Watson, M.; Townend, P.; Chua, T.C.; Pincott, S.J. Rare differential of right iliac fossa pain. ANZ J Surg 2017, 87, 208-209, https://doi.org/10.1111/ans.13755.

7. Nepogodiev, D.; Matthews, J.H.; Morley, G.L.; Bhanderi, S.; Jain, S.; Mohamed, W.; et al. Right Iliac Fossa Pain Treatment (RIFT) Study: protocol for an international, multicentre, prospective observational study. BMJ Open 2018, 8, https://doi.org/10.1136/bmjopen-2017-017574.

8. Zhang, Y.; Bai, J.; Wu, H.; Ying, J.Y. Trapping cells in paper for white blood cell count. Biosensors and Bioelectronics 2015, 69, 121-127, http://dx.doi.org/10.1136/bmjopen-2017-017574.

9. Esperat, M.M.; Golosino, A.J.; Reovoca, P.J.; Sales, M.E. Comparison of WBC Count and Differential Count of Working Students by Their Type of Work. Adventist University of the Philippines 2016, 49.

10. Springer, B.D. The diagnosis of periprosthetic joint infection. J Arthroplasty 2015, 30, 908-911, https://doi.org/10.1016/j.arth.2015.03.042.

11. Graham, G.R.B.; Vijaybhasker, V. Evaluation of Right iliac fossa mass-a retrospective study. J Evolut Med Dent Sci 2016, 5, 200-214, https://doi.org/10.14260/jemds\%2F2016\%2F45

12. Wanders, B.J.; Farrell, G.A.; Adams, T.H.; Groner, W.; Zhao, X.; Jordan, B.; Cremins, J.; Quon, C. Hematology systems and methods 2017.

13. Prakash, J.S.; Samraj, A.; Kumar, G.S.; Vijai, R. A Diagnostic Surprise For A Right Iliac Fossa Mass - A Perforated Ileal Gastrointestinal Stromal Tumour.

J Clin Diagn Res 2017, 11, PD03-PD04, https://dx.doi.org/10.7860\%2FJCDR\%2F2017\%2F27704.10560.

14. Burai, M.; Gameraddin, M.B.; Suliman, A.; Gareeballah, A.; Alagab, F.; Elzaki, M. Pelvic ultrasonographic findings in patients with acute right iliac fossa pain. International Journal of Health \& Allied Sciences 2019, 8, 33, https://doi.org/10.4103/ijhas.IJHAS_6_18.

15. Raptis, D.A.; Eshmuminov, D.; Tschuor, C.; Limani, P.; Neff, T.; Reding, T.; Martens, F.; Renzulli, P.; Widmer, J.D.; Muller, M.K.; Schibli, M.; Lassker, R.; Steinemann, D.C.; Angst, E.; Bosch, M.; Psarianos, K.; Lytras, D.; Graf, R. Diagnostic value of pancreatic stone protein in comparison to white cell count and c 
reactive protein in the diagnosis of acute appendicitis a prospective multicenterdiagnostic accuracy trial. Journal of Surgery 2019.

16. Jagmohan, P.; Dhanda, S.; Singh, P.; Thian, Y.L.; Ang, B.; Quek, S.T. Acute abdomen in cancer patients: Role of imaging in a challenging clinical scenario. European Congress of Radiology 2016, 2016, https://doi.org/10.1594/ecr2016/C-1202.

17. Berger, S. Infectious Diseases of Haiti. GIDEON Informatics Incorporated 2018.

18. del Pozo, G.; Berrocal, T. Gastrointestinal Emergencies in the Infant and Young Child. Radiological Imaging of the Digestive Tract in Infants and Children. Springer; 2016; pp. 61-123.

19. Lynch, D.; Hall, J.; Foucar, K. How I investigate monocytosis. International journal of laboratory hematology 2018, 40, 107-114, https://doi.org/10.1111/ijlh.12776.

20. Nossal, G.J. Life, death and the immune system. Sci Am 1993, 269, 52-62.

21. Barraco, D.; Cerquozzi, S.; Gangat, N.; Patnaik, M.M.; Lasho, T.; Finke, C.; Hanson, C.A.; Ketterling, R.P.; Pardanani, A.; Tefferi, A. Monocytosis in polycythemia vera: clinical and molecular correlates. Am J Hematol 2017, 92, 640-645, https://doi.org/10.1002/ajh.24740.

22. Puigví, L.; Baumann, T.; Fernández, S.; Castro, P.; Pereira, A.; Merino, A. Massive erythrophagocytosis by peripheral monocytes and neutrophils in parvovirus-B19 autoimmune hemolytic anemia. Ann Hematol 2017, 96, 881, https://doi.org/10.1007/s00277-017-2957-2.

23. Soldo, I.; Radisic, B.V.; Bakula, B.; Bakula, M.; Simundic, A. The diagnostic accuracy of clinical and laboratory parameters in the diagnosis of acute appendicitis in the adult emergency department populationa case control pilot study. Biochemia medica 2018, 28, 495-502, https://dx.doi.org/10.11613\%2FBM.2018.030712.

24. Saleem, M.M.; Pervaiz, M.; Chaudhary, I.A. Predictive value of leukocytosis for diagnosing acute appendicitiss. Frequency of Bell's Palsy Patients Getting Steroids At Onset of Their Symptoms 2017, 67, 292.

25. Platon, A.; Frund, C.; Meijers, L.; Perneger, T.; Andereggen, E.; Becker, M.; Poletti, A.H.; Rutschmann, O.T.; Poletti, A.P. Concomitant leukocytosis and lymphopenia predict significant pathology at CT of acute abdomen: a case-control study. BMC emergency medicine 2019, 19, https://dx.doi.org/10.1186\%2Fs12873019-0227-4.

26. Feinberg, J.; Flynn, L.; Woodward, M.; Pennell, C.; Higham, H.; Morgan, L.; Holman, L.; Tully, P.; McCulloch, P. Improving emergency surgical care for patients with right iliac fossa pain at a regional scale: A quality improvement study using the Supported Champions implementation strategy. International Journal of Surgery 2018, 57, 105-110, https://doi.org/10.1016/j.ijsu.2018.08.003.

27. Di Saverio, S.; Tugnoli, G. The Challenge of Clinical Diagnosis of Appendicitis and Nonoperative Management of Patients With Right Lower Abdominal Pain. Ann Surg 2016, 263, e22-e23, https://doi.org/10.1097/SLA.0000000000001025.

28. Di Saverio, S.; Coccolini, F.; Sartelli, M.; Ansaloni, L.; Tugnoli, G. Reply to Letter:"Nonoperative Management of Right Iliac Fossa Pain What Does Really Matter?” Ann Surg 2016,263, e55, https://doi.org/10.1097/SLA.0000000000001335.

29. Gans, S.L.; Pols, M.A.; Stoker, J.; Boermeester, M.A, expert steering group. Guideline for the diagnostic pathway in patients with acute abdominal pain. Dig Surg 2015, 32, 23-31, https://doi.org/10.1159/000371583.

30. Saleem, M.M.; Pervaiz, M.; Chaudhary, I.A. Predictive value of leukocytosis for diagnosing acute appendicitiss. Frequency of Bell's Palsy Patients Getting Steroids At Onset of Their Symptoms 2017, 67, 292.

31. Platon, A.; Frund, C.; Meijers, L.; Perneger, T.; Andereggen, E.; Becker, M.; Halfon, P.A.; Rutschmann, O.T.; Poletti, P.A. Concomitant leukocytosis and lymphopenia predict significant pathology at CT of acute abdomen: a case-control study. BMC emergency medicine 2019, 19, 10, https://doi.org/10.1186/s12873-0190227-4.

32. Di Saverio, S.; Tugnoli, G. The Challenge of Clinical Diagnosis of Appendicitis and Nonoperative Management of Patients With Right Lower Abdominal Pain. Ann Surg 2016, 263, e22-e23, https://doi.org/10.1097/SLA.0000000000001025.

33. Di Saverio, S.; Coccolini, F.; Sartelli, M.; Ansaloni, L.; Tugnoli, G. Reply to Letter:"Nonoperative Management of Right Iliac Fossa Pain What Does Really Matter?" Ann Surg 2016, 263, e55, https://doi.org/10.1097/SLA.0000000000001335.

34. Gans, S.L.; Pols, M.A.; Stoker, J.; Boermeester, M.A.; expert steering group. Guideline for the diagnostic pathway in patients with acute abdominal pain. Dig Surg 2015, 32, 23-31. 